\title{
3 Research Square \\ DNA Double Strand Breaks in the Toxoplasma Gondii-Infected Cells by the Action of Reactive Oxygen Species
}

Haohan Zhuang

Zhejiang University

Chaoqun Yao

Ross University School of Veterinary Medicine

\section{Xianfeng Zhao}

Animals \& plant inspection and quarantine technology center of shenzhen customs

\section{Yi Yang}

Zhejiang University

\section{Xueqiu Chen}

Zhejiang University

\section{Yimin Yang}

Zhejiang University

\section{Siyang Huang}

Institute of comparative medicine, College of veterinary medicine, Yangzhou University, and Jiangsu coinnovation center for prevention and control of important animal infectious diseases and zoonosis, and Jiangsu key laboratory of zoonosis, Yangzhou, Jiangsu province, China.

\section{Lingtao Pan}

Zhejiang University

Aifang Du ( $\square$ afdu@zju.edu.cn )

Zhejiang University https://orcid.org/0000-0002-3796-6621

\section{Research}

Keywords: Toxoplasma gondii, DNA damage, Reactive oxygen species, DNA damage response

Posted Date: June 17th, 2020

DOI: https://doi.org/10.21203/rs.3.rs-35853/v1

License: (c) (1) This work is licensed under a Creative Commons Attribution 4.0 International License.

Read Full License 
Version of Record: A version of this preprint was published at Parasites \& Vectors on September 25th, 2020. See the published version at https://doi.org/10.1186/s13071-020-04324-7. 


\section{Abstract}

Background: Toxoplasma gondii (T. gondii) is an obligate parasite of the warm-blooded animals with a worldwide distribution. Once having entered a host cell, it manipulates host's DNA damage response that is yet to be investigated. The objectives of the present study were three-fold: 1) to assess DNA damages in T. gondii-infected cells in vitro; 2) to ascertain sources causing DNA damage in T. gondii-infected cells; 3 ) to investigate activation of DNA damage response during T. gondii infection.

Methods: HeLa, Vero and HEK293 cells were infected with T. gondii at multiplicity of infection (MOI) of 10:1. Infected cells at $10 \mathrm{~h}, 20 \mathrm{~h}$ or $30 \mathrm{~h}$ post infection were analyzed for a DNA double strand breaks (DSBs) biomarker $\mathrm{yH} 2 \mathrm{AX}$ using Western blot and immunofluorescence assay. Reactive oxygen species (ROS) levels were examined using 2',7'-dichlorodihydrofluorescein diacetate (H2DCFDA), and the impact of ROS on DNA damage was assessed by inhibition using a ROS inhibitor N-acetylcysteine (NAC). Lastly, DNA damage response in these $T$. gondii-infected cells was evaluated by detecting the expression of active form of ataxia telangiectasia mutated/checkpoint kinase 2 (ATM/CHK2) with Western blot.

Results: Compared to uninfected cells, $\mathrm{yH} 2 \mathrm{AX}$ expression in the infected HeLa cells at $10 \mathrm{~h}, 20 \mathrm{~h}$, and $30 \mathrm{~h}$ was increased over time during T. gondii infection. NAC treatment reduced ROS level in host cells and significantly decreased the expression of $\mathrm{yH} 2 \mathrm{AX}$. Expression of phosphorylated ATM/CHK2 was elevated in T. gondii-infected cells.

Conclusion: T. gondii infection triggered DNA DSBs with ROS as a major player in host cells in vitro. It also concomitantly activated DNA damage response pathway ATM/CHK2. T. gondii struggles a balance between survival and apoptosis of its host cells for the benefit of its own survival.

\section{Background}

The protozoan parasite Toxoplasma gondii ( $T$. gondii) infects almost all warm-blooded creatures including humans worldwide [1]. It modulates some biological processes of the infected cell, such as autophagy and apoptosis, to facilitate its survival and proliferation [2, 3]. A few studies have previously shown that $T$. gondii infections trigger DNA damage in the retina and the peripheral blood cells of infected mice $[4,5]$.

DNA damage may exhibit many different forms including single strand breaks (SSBs), double strand breaks (DSBs), missing bases and chemical modification of bases etc. [6]. It may be caused by various factors of both endogenous and exogenous origin. Examples of each is reactive oxygen species (ROS); and ultraviolet light and chemical reagents, respectively [7].

ROS is naturally generated from metabolic and biochemical reactions and is a major source of the endogenous stress [8]. Superoxide, hydrogen peroxide, hydroxyl radicals and singlet oxygen are all ROS. They can oxidize DNA molecules leading to base oxidization, SSBs and DSBs [9]. Elevated ROS levels have been previously reported in $T$. gondii-infected macrophages [10]. However, how T. gondii influences 
DNA damage, what the DNA damage responses are, and whether and how ROS triggers DNA damage in the $T$. gondii-infected cells all remain to be elucidated. Here, we used a well-characterized marker of DNA DSBs, $\gamma \mathrm{H} 2 \mathrm{AX}$ to demonstrate DNA damage in T. gondii-infected HeLa cells. The levels of $\mathrm{YH} 2 \mathrm{AX}$ increased over time during $T$. gondii infection and ROS was the major player in the DNA DSBs. Furthermore, DNA damage response pathway ataxia telangiectasia mutated/checkpoint kinase 2 (ATM/CHK2) was activated, suggesting the possible role of DNA damage in regulation of other biological processes in the T. gondii-infected host cells.

\section{Methods}

\section{Host cells, parasites and mice}

Vero (African green monkey kidney cells), HEK293T and HeLa cells were obtained from the Cell Bank of the Chinese Academy of Sciences (Shanghai, China). The cells were cultured in DMEM (Biological Industries, Israel) supplemented with 10\% fetal bovine serum (FBS) (Biological Industries, Israel) and 1\% penicillin-streptomycin-glutamine (Gibco, USA). All cell lines were treated with MycAway ${ }^{\mathrm{TM}}$ elimination reagent (Yeason, China). Mycoplasma testing was done using One-Step Mycoplasma Detection Kit (Yeason, China). T. gondii strain RH $\Delta k u 80$ strain and EGFP-RH $\Delta k u 80$ strain were maintained in our own lab as tachyzoites in Vero cells by serial passage according to the previous report [11]. Six-week-old BALB/c mice were obtained from Shanghai SLAC Laboratory Animal Co., Ltd (Shanghai, China), and housed in a ventilated cage kept under a conditioned temperature of $25^{\circ} \mathrm{C}$ with a light/dark cycle of $14 \mathrm{~h} / 10 \mathrm{~h}$.

\section{Primary antibodies, secondary antibodies and murine sera}

The antibodies to the following molecules were purchased from various sources as indicated. $\mathrm{YH} 2 \mathrm{AX}$ (Cell Signaling Technology, USA) was used to document DNA DSBs. Actin and cleaved caspase 3 (Abcam, UK) were used as loading control and apoptosis indicator, respectively. ATM, ATM-S1981, CHK2 and CHK2-T68 (Cell Signaling Technology, USA) were used to indicate DNA damage response. HRPconjugated goat anti-mouse IgG and HRP-conjugated goat anti-rabbit IgG (Fude, China) were used in Western blot. Donkey anti-mouse Alexa Fluor 488 and goat anti-rabbit Alexa Fluor 594 (ThermoFisher, USA) were used in immunofluorescence assay. Anti-T. gondii inner membrane complex 1 (IMC1) and surface protein 1 (SAG1) mouse sera were kind gifts from colleagues Miss Mi Lin and Miss Mingxiu Zhao. They were used to detect $T$. gondii in immunofluorescence assay and Western blot, respectively. T. gondii positive serum was harvested from BALB/c mice 6 days post infection (PI) and used to block invasion of T. gondii into HeLa cells. Negative serum was harvested from the same mice prior to infection and used as control.

\section{Western blot}

Western blot was carried out as previously described [11]. Briefly, cellular lysis was achieved by incubation for 30 minutes in ice-cold radioimmunoprecipitation assay buffer (RIPA) lysis buffer 
supplemented with a protease inhibitor cocktail (Bimake, China). The soluble proteins derived from the supernatants of the centrifugation of the cellular lysates at $12,000 \cdot \mathrm{g}, 4^{\circ} \mathrm{C}$ for $10 \mathrm{~min}$ were measured using a BCA assay kit (Fude, China). They were then mixed with SDS-PAGE loading buffer and separated by SDS-PAGE. The $0.22 \mu \mathrm{m}$ PVDF membrane (Millipore, USA) blotted with proteins was blocked with $5 \%$ skimmed milk (Sangon, China) in Tris buffered saline with 0.5\% Tween-20 (TBST) followed by incubation in suitable primary antibodies. The membranes were then probed with appropriate HRP-conjugated secondary antibodies (Fude, China). Membranes were rinsed thrice in TBS (10 minutes each) at each interval. Signals were immediately documented using ChemiDoc $^{\mathrm{TM}}$ chemiluminescence system (Biorad, USA) after membranes were subjected to ECL substrates (Fude, China).

\section{Immunofluorescence assay}

Immunofluorescence microscopy was carried out as described [10]. Briefly, cells grown on coverslips in 24-well plate were fixed with $4 \%$ paraformaldehyde in phosphate buffered saline (PBS) for 10 minutes and permeabilized with $0.25 \%$ triton-PBS for 10 minutes. They were incubated with the primary antibodies for $1 \mathrm{~h}$ after being blocked with $1 \%$ bovine serum albumin for $1 \mathrm{~h}$ followed by submerging in suitable Alexa-fluor-conjugated secondary antibodies for $1 \mathrm{~h}$ in dark. Afterwards they were counterstained with DAPI (Sigma,USA) for 1 minute. At each interval, the cells were rinsed thrice with PBS (10 minutes each). The coverslips were then mounted and images were obtained using Olympus IX81 FV1000 confocal microscope (Olympus, Japan).

\section{ROS measurement}

ROS measurement was carried out as previously described [12]. Briefly, HeLa cells were seeded on 24-well plates and infected with $T$. gondii RH strain at a multiplicity of infection (MOI) of 10:1. Twenty-four hours $\mathrm{Pl}$, infected cells were treated with the ROS inhibitor N-acetylcysteine (NAC) at $50 \mu \mathrm{m}$ for $1 \mathrm{~h}, 2 \mathrm{~h}$ or $4 \mathrm{~h}$. They were then incubated in $10 \mu \mathrm{m}$ 2',7'-dichlorodihydrofluorescein diacetate (H2DCFDA, MCE, USA) in dark for $30 \mathrm{~min}$ in an incubator set at $37^{\circ} \mathrm{C}$ and $5 \% \mathrm{CO}_{2}$ airflow after being rinsed 3 times in PBS. H2DCFDA is a nonfluoresent precursor that is intracellularly oxidized by ROS to form highly fluorescent product DCF. Finally, fluorescence signals of cells were measured by Synergy 2 plate reader (Biotek, USA) at $485 \mathrm{~nm}$ exiting wavelength.

\section{Quantification and statistical analysis}

Quantifications of Western-blot protein bands were done by Image J. Western blot data from Image $\mathrm{J}$ and fluorescence data from plate reader representing triplicate samples were analyzed by GraphPad Prism 7.0. Analysis was done by comparing the mean of each treated groups with the mean of the control group. Error bars represent standard deviation of the mean. Statistical significance was determined by one-way ANOVA. $P \leq 0.05$ was considered significant.

\section{Results}

T. gondii infection triggered DNA DSBs in host cells in vitro 
DSBs are one of the most common forms of DNA damage [13]. Phosphorylation of H2AX at the ser139 position called $\mathrm{YH} 2 \mathrm{AX}$ is a well-characterized marker of DSBs in mammalian cells [14]. To study $T$. gondii infection on host cell DNA damage in vitro, we infected Vero, HEK293T or HeLa cells with T. gondii $\mathrm{RH} \Delta k u 80$ strain parasites at a $\mathrm{MOI}$ of 10:1. Similar effect was observed among all the three types of cells upon T. gondii infections. Hela cells were used throughout the entire manuscript unless the other cell type was specifically identified. The cells were harvested at $0 \mathrm{~h}$ (uninfected control) $10 \mathrm{~h}, 20 \mathrm{~h}$ or $30 \mathrm{~h} \mathrm{PI}$ and analyzed by Western blot to detect $\mathrm{YH} 2 \mathrm{AX}$. Compared to $0 \mathrm{~h}, \mathrm{YH} 2 \mathrm{AX}$ expression in the infected HeLa cells at $10 \mathrm{~h}, 20 \mathrm{~h}$, and $30 \mathrm{~h}$ had increased approximately 10-, 85- and 90-fold, respectively (Fig. 1A\&B). A similar trend was observed in the infected Vero and HEK293T cells as well (data not shown). We next determined the source of $\mathrm{YH} 2 \mathrm{AX}$ since Fig. 1A\&B did not show whether it originated from the infected host cells, parasites themselves or both. We purified tachyzoites from the infected Hela cells and contrasted their levels of $\mathrm{yH} 2 \mathrm{AX}$ to those of the infected cells. $\mathrm{yH} 2 \mathrm{AX}$ was abundantly detected in the infected HeLa cells. In contrast, the levels of $\mathrm{yH} 2 \mathrm{AX}$ in parasites were below detectable level (Fig. 1C). These data clearly showed that $\mathrm{yH} 2 \mathrm{AX}$ originated from the host cells rather than the parasites themselves. To further confirm $\mathrm{yH} 2 \mathrm{AX}$ expression and its location upon $T$. gondii infection, we carried out indirect immunofluorescence using anti-IMC1 mouse serum and $\mathrm{YH} 2 \mathrm{AX}$ antibody to detect $T$. gondii and DNA damage, respectively. Relative to uninfected cells, elevated $\mathrm{yH} 2 \mathrm{AX}$ signals were detected in the nuclei of T. gondii-infected HeLa cells (Fig. 1D). Taken together, our data unequivocally demonstrated that T. gondii infection induced DSBs in host cells in vitro.

\section{T. gondii induced DSBs were irrelevant to apoptosis and depended on its invasion}

It has been reported that $\mathrm{\gamma H} 2 \mathrm{AX}$ occurs in early apoptosis when DNA fragmentation just begins to start [15]. T. gondii infection may initiate apoptosis in some type of cells whereas it may inhibit apoptosis in others [16]. We next tested whether apoptosis influenced $\mathrm{YH} 2 \mathrm{AX}$ production during $T$. gondii infection. To this end, HeLa cells were treated with staurosporine, an apoptosis inducer [17], at $1 \mu \mathrm{m}$ for $4 \mathrm{~h}$ and apoptosis was monitored by Western blot of cleaved caspase 3 . The latter is an early apoptotic event [18]. While $\mathrm{YH} 2 \mathrm{AX}$ were detected in both staurosporine-treated HeLa cells and $T$. gondii infected $(12 \mathrm{~h}$ and $24 \mathrm{~h}$ ) HeLa cells, cleaved caspase 3 was only detected in staurosporine-treated cells with no trace of its detection in $T$. gondii infected cells (Fig. 2A/2B). These data clearly showed that $T$. gondii infection did not trigger apoptosis in HeLa cells, which unequivocally ruled out that apoptosis was involved in their DNA damage.

During early infection, T. gondii invades host cells and leads to the formation of a parasitophorous vacuole to facilitate its proliferation [19]. We next examined whether T. gondii triggered host DNA damage before invasion. To this end, EGFP-RH $\triangle k u 80 \mathrm{~T}$. gondii tachyzoites were incubated with either positive serum from $T$. gondirinfected mice or negative control serum for $1 \mathrm{~h}$ at $37^{\circ} \mathrm{C}$ prior to infection. The positive serum was used to block the invasion of $T$. gondii. HeLa cells were then infected with serumtreated T. gondii at a MOI of 10:1, infected cells were imaged by fluorescence microscopy detecting EGFP or harvested for Western blot analysis of $\mathrm{yH} 2 \mathrm{AX} 20 \mathrm{~h} \mathrm{PI}$. Compared with negative serum treatment, positive serum treatment dramatically blocked invasion of $T$. gondii (data not shown), and decreased 
yH2AX levels by approximately 98\% (Fig. 2C/2D). These results strongly indicating that induction of host DNA damage depends on the invasion of $T$. gondii.

\section{ROS was associated with host DNA damage}

ROS induces oxidative stress, which turns out to cause damages to macromolecules such as proteins, lipids, and DNAs [20]. Multiple studies have implicated pathogen-induced ROS in host cell DNA damage $[21,22,23,24,25]$. Elevated ROS levels have been reported in host cells during $T$. gondii infection $[10,26]$. We hypothesized that ROS causes host DNA damage during T. gondii infection. To test this hypothesis, we treated $T$. gondii infected HeLa cells with N-acetylcysteine (NAC), a ROS inhibitor. NAC was applied to the infected cells $24 \mathrm{~h} \mathrm{PI}$ for up to $4 \mathrm{~h}$. Two methods were used to gauge the impact of ROS on host DNA damage. First, ROS levels of uninfected cells, host cells and NAC-treated host cells were analyzed using H2DCHFA, a nonfluorescent precursor to be converted by ROS to fluorescent DCF. The higher ROS level, the stronger florescence reaction produces. The second method was to monitor generation of $\mathrm{yH} 2 \mathrm{AX}$ by Western blot and immunofluorescence analyses. Results shown that ROS levels in the infected Hela cells increased by approximately $70 \%$ compared to those of uninfected cells $24 \mathrm{~h} \mathrm{PI}$. NAC treatment for as little as $1 \mathrm{~h}$ completely offset the influence of $T$. gondii infection by bringing the ROS levels down almost to the basic level of the uninfected cells (Fig. 3A). Western blot showed that compared to those of the untreated infected host cells, $\mathrm{yH} 2 \mathrm{AX}$ levels in the NAC-treated infected host cells reduced by approximately $85 \%$, $85 \%$ and $70 \%$ at 1,2 and 4 hours of NAC treatment, respectively (Fig. 3B/3C). Immunofluorescence analyses further confirmed reduced expression of $\mathrm{YH} 2 \mathrm{AX}$ in NAC-treated host cells compared to untreated host cells (Fig. 3D). These two lines of evidence suggested that diminishing ROS by NAC greatly reduced $\mathrm{YH} 2 \mathrm{AX}$ levels in infected cells, indicating that ROS leads to DNA damage during T. gondii infection.

\section{Host DNA damage response pathway ATM/CHK2 was activated by T. gondii infection}

DNA damage response is triggered upon DNA damage in eukaryotic cells. A network of kinase pathways is involved in this biological process, among which ATM/CHK2 and ATM RAD3-related/checkpoint kinase 1 (ATR/CHK1) are two main pathways responding to DSBs and SSBs, respectively [13]. Since we had already detected DSBs in host cells, we then examined whether ATM/CHK2 pathway was activated in the T. gondii-infected cells. ATM-S1981 and CHK2-T68 are the functionally activated form of ATM and CHK2, respectively. The expression of ATM-S1981 and CHK2-T68 increased approximately 10, 65, 70 and 0, 15, 25 folds, respectively, at $10 \mathrm{~h}, 20 \mathrm{~h}$ and $30 \mathrm{~h} \mathrm{PI}$ compared to the uninfected controls of $0 \mathrm{~h}$ (Fig. 4A/B/C). This result indicated ATM/CHK2 pathway was activated during T. gondii infection.

\section{Discussion}

DNA damage can be classified into SSBs, DSBs, and chemical modification of bases etc. These different types of DNA damage can be detected by various markers. We used $\mathrm{yH} 2 \mathrm{AX}$ to detect DNA DSBs in the $T$. gondii infected cells. Other types of DNA damage in the eukaryotic cells can be identified by corresponding suitable markers. For example, anti-8oxoG antibody can be used to detect chemical 
modification of DNA bases under oxidative stress $[27,28]$. Here, DSBs were clearly demonstrated in the $T$. gondii-infected host cells. Evaluation of other types of DNA damage in these cells needs to be further performed.

It has been reported that $T$. gondii infection inhibits apoptosis of host cells [29]. Our data that $T$. gondii infections do not cause apoptosis in its host cells align well with these earlier reports even though they do not exactly confirm inhibition of apoptosis in the infected cells. In our experiment of blocking invasion of T. gondii, one shortcoming of using murine serum to inhibit $T$. gondiis invasion of host cells is that there might exist antibodies to the molecules that play important roles other than its invasion. Reagents that have been proven to block this parasite invasion are alternatives. This can be achieved by reagent's action on either the tachyzoites of $T$. gondii parasite or host cell themselves. One example of the former is protease inhibitors such as BAY11-7082 [30]. The latter includes dynamin inhibitor such as dynasore, a small chemical compound that inhibits dynamin GTPase activity [31]. Due to the technical challenges these compounds were not used in the current study. Nevertheless, the murine serum containing polyclonal antibodies used in the current study indeed block the parasites' invasion of Hela cells.

Our data demonstrate that $T$. gondii infection causes significant increase in ROS level in HeLa cells. Although consistent with some earlier reports $[10,26]$, these are clearly contradicted to at least one other study. Decreased levels of ROS were observed in the T. gondii-infected ARPE-19 cells, a human RPE cell line, that had also been exposed to $\mathrm{H}_{2} \mathrm{O}_{2}$ treatment, and T. gondii-infected ARPE- 19 cells at a MOI of 5:1 without $\mathrm{H}_{2} \mathrm{O}_{2}$ treatment showed ROS levels very similar to the uninfected controls [29]. These contradicted results might be due to different type of cells, i.e., HeLa versus ARPE-19, and different MOI of 10:1 and 5:1. Furthermore, DSBs can be repaired rapidly (shown as decreased $\mathrm{YH} 2 \mathrm{AX}$ ) within $1 \mathrm{~h}$ of ROS removal by NAC. The repairing could have been documented occurring in minutes if shorter time points in minutes had been included in our experiment.

Activation of ATM/CHK2 pathway has been reported involved in many biological processes including DNA damage repair, cell cycle control and apoptosis etc. For example, active ATM/CHK2 pathway leads to phosphorylation of P53, which is a well-known transcription factor. On one hand, phosphorylation of P53 at Ser25, Ser20 and Ser33 upregulates the expression of DNA binding protein 2 (DDB2), E3 ubiquitinprotein ligase MDM2 and CDC25a. These three proteins are the key players in DNA damage repair and cell cycle control, which contribute to survival of wounded cells [32]. On the other hand, phosphorylation of P53 at Ser46 by ATM/CHK2 pathway leads to the expression of pro-apoptotic genes, thereby stimulating apoptosis in wounded cells [33]. We propose that activation of ATM/CHK2 pathway plays a vital role in the host cells to keep a calculated balance between survival and apoptosis during T. gondii infection, probably for the benefit of parasite survival.

Identification of parasite's molecules causing host cell DNA damage and their molecular interactions with host cells are beyond the scope of the current study. However, it has been reported that the ROP18 kinase of $T$. gondii interacts with host proteins involving DNA repair and other functions [34]. Ocular and brain lesions caused by $T$. gondii infections are confirmed in human individuals with significant DNA repair 
genes polymorphism [35]. Therefore, T. gondii virulence factors associated with DNA damage and host susceptibility to this damage should be further addressed.

\section{Conclusion}

Our studies clearly showed that T. gondii infection induced DNA double strand breaks in host cells. This process was unrelated to apoptosis and only occurred after the invasion of $T$. gondii. Reactive oxygen species was verified as the major factor for DNA double strand breaks in host cells. Host DNA damage response pathway ATM/CHK2 was activated during T. gondii infection, suggesting DNA damage process may trickle other biological processes as well. To our knowledge, this is the first to document that DNA double strand breaks occur in the $T$. gondii-infected host cells. More experiments are needed to explore the molecular network of DNA double strand breaks as well as other types of DNA damage in host cells in the future.

\section{Abbreviations}

$\mathrm{MOI}$

multiplicity of infection; ROS:Reactive oxygen species; NAC:N-acetylcysteine; ATM/CHK2:ataxia telangiectasia mutated/checkpoint kinase 2; SSBs:single strand breaks; DSBs:double strand breaks; FBS:fetal bovine serum; DMEM:Dulbecco's Modified Eagle Medium; IMC1:inner membrane complex 1; SAG1:surface protein 1; TBS:Tris buffered saline; PBS:phosphate buffered saline; H2DCFDA:2',7'dichlorodihydrofluorescein diacetate.

\section{Declarations}

\section{Acknowledgments}

We are very grateful to the colleagues Miss Mi Lin and Miss Mingxiu Zhao for their sharing anti-T. gondii IMC1 and SAG1 murine sera, respectively. We also thank Dr. Weiren Dong and Dr. Ying Shan of College of Animal Sciences, Zhejiang University for their technical help on operating Plate Reader and Confocal microscope, respectively.

\section{Funding}

This project was supported by the National Natural Science Foundation of China (grant No. 31672543), the National Natural Science Foundation of China (Grant No. 31472184), Zhejiang Province "Sannongliufang" Science and Technology Cooperation Project\grant No. 2020SNLF007区\and the Science and Technology Department of Zhejiang (grant NO. 2012C12009-2).

\section{Author information}

\section{Affiliations}


Institute of Preventive Veterinary Medicine, Zhejiang Provincial Key Laboratory of Preventive Veterinary Medicine, College of Animal Sciences, Zhejiang University, Hangzhou 310058, PR China.

Haohan Zhuang, Yi Yang, Xueqiu Chen, Yimin Yang, Lingtao Pan \& Aifang Du

Ross University School of Veterinary Medicine and One Health Center for Zoonoses and Tropical Veterinary Medicine, Ross University School of Veterinary Medicine, Basseterre, St. Kitts, West Indies.

Chaoqun Yao

Animals \& Plant Inspection and Quarantine Technology Center of Shenzhen Customs $\square$ Shenzhen 518045, PR China.

Xianfeng Zhao

Institute of Comparative Medicine, College of Veterinary Medicine, Yangzhou University, and Jiangsu Coinnovation Center for Prevention and Control of Important Animal Infectious Diseases and Zoonosis, and Jiangsu Key Laboratory of Zoonosis, Yangzhou, Jiangsu Province 225009, PR China.

Siyang Huang

Contributions

Aifang Du, Yi Yang, Yimin Yang, Xianfeng Zhao and Siyang Huang conceived and supported the study, Haohan Zhuang designed and performed the laboratory work, Lingtao Pan and Chaoqun Yao did the data analysis, Xueqiu Chen purchased experimental materials, Haohan Zhuang and Chaoqun Yao wrote the manuscript. All authors read and approved the final version of the manuscript.

Corresponding author

Address correspondence to Aifang Du

Ethics declarations

Ethics approval and consent to participate

Animal experiments were carried out under strict adherence to the guidelines on use of experimental animals of the People's Republic of China. Animal use for this study was approved by the Experimental Animal Ethics Committee of Zhejiang University (permit number: ZJU20160240).

Consent for publication

Not applicable.

Competing interests 
The authors declare that they have no competing interests.

Availability Of Data And Material

Data supporting the conclusions of this article are included within the article. Data and materials can be available upon reasonable request to the corresponding author.

\section{References}

1. Molan A, Nosaka K, Hunter M, Wang W. Global status of Toxoplasma gondii infection: systematic review and prevalence snapshots. Trop Biomed. 2019;36 4:898-925. <Go to ISI>://WOS:000500954500011.

2. $10.1155 / 2019 / 6152489$

Mammari N, Halabi MA, Yaacoub S, Chlala H, Darde M-L, Courtioux B. Toxoplasma gondii Modulates the Host Cell Responses: An Overview of Apoptosis Pathways. Biomed Res Int. 2019; doi: 10.1155/2019/6152489. <Go to ISI>://WOS:000464693500001.

3. $10.1074 / \mathrm{jbc} . M 807890200$

Wang Y, Weiss LM, Orlofsky A. Host Cell Autophagy Is Induced by Toxoplasma gondii and Contributes to Parasite Growth. J Biol Chem. 2009;284 3:1694 - 701; doi: 10.1074/jbc.M807890200. $<$ Go to ISI>://WOS:000262330100038.

4. 10.1016/j.mrgentox.2004.01.007

Ribeiro DA, Pereira PCM, Machado JM, Silva SB, Pessoa AWP, Salvadori DMF. Does toxoplasmosis cause DNA damage? An evaluation in isogenic mice under normal diet or dietary restriction. Mutat Res-Gen Tox En. 2004;559 1-2:169 - 76; doi: 10.1016/j.mrgentox.2004.01.007. <Go to ISI>://WOS:000221014200017.

5. 10.3980/j.issn.2222-3959.2014.03.08

El-Sayed NM, Aly EM. Toxoplasma gondii infection can induce retinal DNA damage: an experimental study. Int J Ophthalmol. 2014;7 3:431-6; doi: 10.3980/j.issn.2222-3959.2014.03.08. <Go to ISI>://WOS:000337658400008.

6. $10.1038 /$ emboj. 2008.15

Hakem R. DNA-damage repair; the good, the bad, and the ugly. Embo J. 2008;27 4:589-605; doi: 10.1038/emboj.2008.15. <Go to ISI:://WOS:000253409300002.

7. $10.1016 /$ j.gde.2003.11.001

Friedberg EC, McDaniel LD, Schultz RA. The role of endogenous and exogenous DNA damage and mutagenesis. Curr Opin Genet Dev. 2004;14 1:5-10; doi: 10.1016/j.gde.2003.11.001. <Go to ISI>://WOS:000188978200002.

8. Kryston TB, Georgiev AB, Pissis P, Georgakilas AG. Role of oxidative stress and DNA damage in human carcinogenesis. Mutat Res. 2011;711 1-2:193-201; doi: 10.1016/j.mrfmmm.2010.12.016. <Go to ISI>://WOS:000291914700020. 
9. 10.1016/j.redox.2018.101084

Srinivas US, Tan BWQ, Vellayappan BA, Jeyasekharan AD. ROS and the DNA damage response in cancer. Redox Biol. 2019;25; doi: 10.1016/j.redox.2018.101084. <Go to ISI>://WOS:000498849800003.

10. $10.1128 / \mathrm{mBio} .01393-18$

Matta SK, Patten K, Wang Q, Kim B-H, MacMicking JD, Sibley LD. NADPH Oxidase and Guanylate Binding Protein 5 Restrict Survival of Avirulent Type III Strains of Toxoplasma gondii in Naive Macrophages. mBio. 2018;9 4; doi: 10.1128/mBio.01393-18. <Go to ISI>://WOS:000443884300071.

11. Sun H, Wang S, Zhao X, Yao C, Zhuang H, Huang Y, et al. Targeted overexpression of cyclic AMPdependent protein kinase subunit in Toxoplasma gondii promotes replication and virulence in host cells. Vet Parasitol. 2017;243:248 - 55; doi: 10.1016/j.vetpar.2017.06.002. <Go to ISI>://WOS:000409287900042.

12. $10.1016 /$ j.celrep.2019.06.002

Raihan O, Brishti A, Li Q, Zhang Q, Li D, Li X, et al. SFRS11 Loss Leads to Aging-Associated Cognitive Decline by Modulating LRP8 and ApoE. Cell Rep. 2019;28 1:78-+; doi: 10.1016/j.celrep.2019.06.002. $<$ Go to ISI:://WOS:000473423800008.

13. $10.15252 /$ embj.2019101801

Lanz MC, Dibitetto D, Smolka MB. DNA damage kinase signaling: checkpoint and repair at 30 years. Embo J. 2019;38 18; doi: 10.15252/embj.2019101801. <Go to ISI>://WOS:000486204200005.

14. Sharma A, Singh K, Almasan A. Histone H2AX phosphorylation: a marker for DNA damage. Meth Mol Biol (Clifton, NJ). 2012;920:613 - 26; doi: 10.1007/978-1-61779-998-3_40. <Go to ISI>://MEDLINE:22941631.

15. $10.1074 /$ jbc. 275.13 .9390

Rogakou EP, Nieves-Neira W, Boon C, Pommier Y, Bonner WM. Initiation of DNA fragmentation during apoptosis induces phosphorylation of H2AX histone at serine 139. J Biol Chem. 2000;275 13:9390-5; doi: $10.1074 / \mathrm{jbc} .275 .13 .9390$. <Go to ISI>://WOS:000086206500047.

16. $10.1016 / \mathrm{s} 1471-4922(01) 02016-5$

Luder CGK, Gross U, Lopes MF. Intracellular protozoan parasites and apoptosis: diverse strategies to modulate parasite-host interactions. Trends Parasitol. 2001;17 10:480-6; doi: 10.1016/s14714922(01)02016-5. <Go to |SI>://WOS:000171456700010.

17. $10.1038 /$ sj.onc. 1204436

Belmokhtar CA, Hillion J, Segal-Bendirdjian E. Staurosporine induces apoptosis through both caspase-dependent and caspase-independent mechanisms. Oncogene. 2001;20 26:3354-62; doi: 10.1038/sj.onc.1204436. <Go to ISI>://WOS:000169248800006.

18. $10.1042 /$ bj20090825

Walters J, Pop C, Scott FL, Drag M, Swartz P, Mattos C, et al. A constitutively active and uninhibitable caspase-3 zymogen efficiently induces apoptosis. Bioch J. 2009;424:335 - 45; doi:

10.1042/bj20090825. <Go to ISI>://WOS:000273211600002. 
19. 10.1016/j.mib.2019.07.002

Rastogi S, Cygan AM, Boothroyd JC. Translocation of effector proteins into host cells by Toxoplasma gondii. Curr Opin Microbiol. 2019;52:130-8; doi: 10.1016/j.mib.2019.07.002. <Go to ISI>://WOS:000504783100021.

20. 10.1186/1477-3163-5-14

Waris G, Ahsan H. Reactive oxygen species: role in the development of cancer and various chronic conditions. J Carcinog. 2006;5:14-; doi: 10.1186/1477-3163-5-14. <Go to ISI>://MEDLINE:16689993.

21. $10.1111 /$ hel. 12631

Fu L, Xie C. A lucid review of Helicobacter pylori-induced DNA damage in gastric cancer. Helicobacter. 2019;24 5; doi: 10.1111/hel.12631. <Go to ISI>://WOS:000474896400001.

22. Ribeiro DA, Calvi SA, Picka MM, Persi E, de Carvalho TB, Caetano PK, et al. DNA damage and nitric oxide synthesis in experimentally infected balb/c mice with Trypanosoma cruzi. Exp Parasitol. 2007;116 3:296-301; doi: 10.1016/j.exppara.2006.12.007. <Go to ISI>://WOS:000247662500014.

23. 10.1016/j.mrgentox.2005.04.012

Kocyigit A, Keles H, Selek S, Guzel S, Celik H, Erel O. Increased DNA damage and oxidative stress in patients with cutaneous leishmaniasis. Mutat Res-Gen Tox En. 2005;585 1-2:71 - 8; doi:

10.1016/j.mrgentox.2005.04.012. <Go to ISI>://WOS:000230952100008.

24. 10.1371/journal.ppat.1003711

Zgur-Bertok D. DNA Damage Repair and Bacterial Pathogens. Plos Pathog. 2013;9 11; doi: 10.1371/journal.ppat.1003711. <Go to ISI>://WOS:000330386900004.

25. $10.3390 /$ cancers 6042155

Chen Y, Williams V, Filippova M, Filippov V, Duerksen-Hughes P. Viral Carcinogenesis: Factors Inducing DNA Damage and Virus Integration. Cancers. 2014;6 4:2155-86; doi:

10.3390/cancers6042155. <Go to ISI>://WOS:000209950800014.

26. 10.1371/journal.pone.0066306

Zhou W, Quan J-H, Lee Y-H, Shin D-W, Cha G-H. Toxoplasma gondii Proliferation Require DownRegulation of Host Nox4 Expression via Activation of PI3 Kinase/Akt Signaling Pathway. Plos One. 2013;8 6; doi: 10.1371/journal.pone.0066306. <Go to ISI>://WOS:000320576400081.

27. 10.1016/j.molcel.2010.09.019

Ciccia A, Elledge SJ. The DNA Damage Response: Making It Safe to Play with Knives. Mol Cell. 2010;40 2:179-204; doi: 10.1016/j.molcel.2010.09.019. <Go to ISI>://WOS:000284028100003.

28. Ravanat JL, Cadet J, Douki T. Oxidatively Generated DNA Lesions as Potential Biomarkers of In Vivo Oxidative Stress. Curr Mol Med. 2012;12 6:655 - 71; doi: 10.2174/156652412800792651. <Go to ISI>://WOS:000305583400002.

29. 10.1111/j.1755-3768.2011.02113.x

Choi S-H, Park SJ, Cha G-H, Quan JH, Chang N-S, Ahn M-H, et al. Toxoplasma gondii protects against $\mathrm{H} 2 \mathrm{O} 2$-induced apoptosis in ARPE-19 cells through the transcriptional regulation of apoptotic 
elements and downregulation of the p38 MAPK pathway. Acta Ophthalmol. 2011;89 4:E350-E6; doi: 10.1111/j.1755-3768.2011.02113.x. <Go to ISI>://WOS:000291057200010.

30. $10.1007 / \mathrm{s} 00436-020-06673-9$

Han Y, Adeyemi OS, Bin Kabir MH, Kato K. Screening of compound libraries for inhibitors of Toxoplasma growth and invasion. Parasitol Res. 2020;119 5:1675-81; doi: 10.1007/s00436-02006673-9. <Go to ISI>://WOS:000522694200001.

31. 10.1111/j.1574-6968.2009.01799.x

Caldas LA, Attias M, de Souza W. Dynamin inhibitor impairs Toxoplasma gondii invasion. FEMS Microbiol Lett. 2009;301 1:103-8; doi: 10.1111/j.1574-6968.2009.01799.x. <Go to ISI>://WOS:000271466400013.

32. $10.1038 /$ nrc. 2015.2

Roos WP, Thomas AD, Kaina B. DNA damage and the balance between survival and death in cancer biology. Nat Rev Cancer. 2016;16 1:20-33; doi: 10.1038/nrc.2015.2. <Go to ISI>://WOS:000372426400002.

33. 10.1038 /onc. 2008.315

Pietsch EC, Sykes SM, McMahon SB, Murphy ME. The p53 family and programmed cell death. Oncogene. 2008;27 50:6507-21; doi: 10.1038/onc.2008.315. <Go to ISI>://WOS:000260501600009.

34. 10.1016/j.actatropica.2012.02.001

Cheng L, Chen Y, Chen L, Shen Y, Shen J, An R, et al. Interactions between the ROP18 kinase and host cell proteins that aid in the parasitism of Toxoplasma gondii. Acta Trop. 2012;122 3:255 - 60; doi: 10.1016/j.actatropica.2012.02.001. <Go to ISI>://WOS:000303291900005.

35. 10.1007/s00203-013-0944-0

Smolarz B, Wilczynski J, Nowakowska D. DNA repair mechanisms and Toxoplasma gondii infection. Arch Microbiol. 2014;196 1:1-8; doi: 10.1007/s00203-013-0944-0. <Go to ISI>://WOS:000329605500001.

\section{Figures}




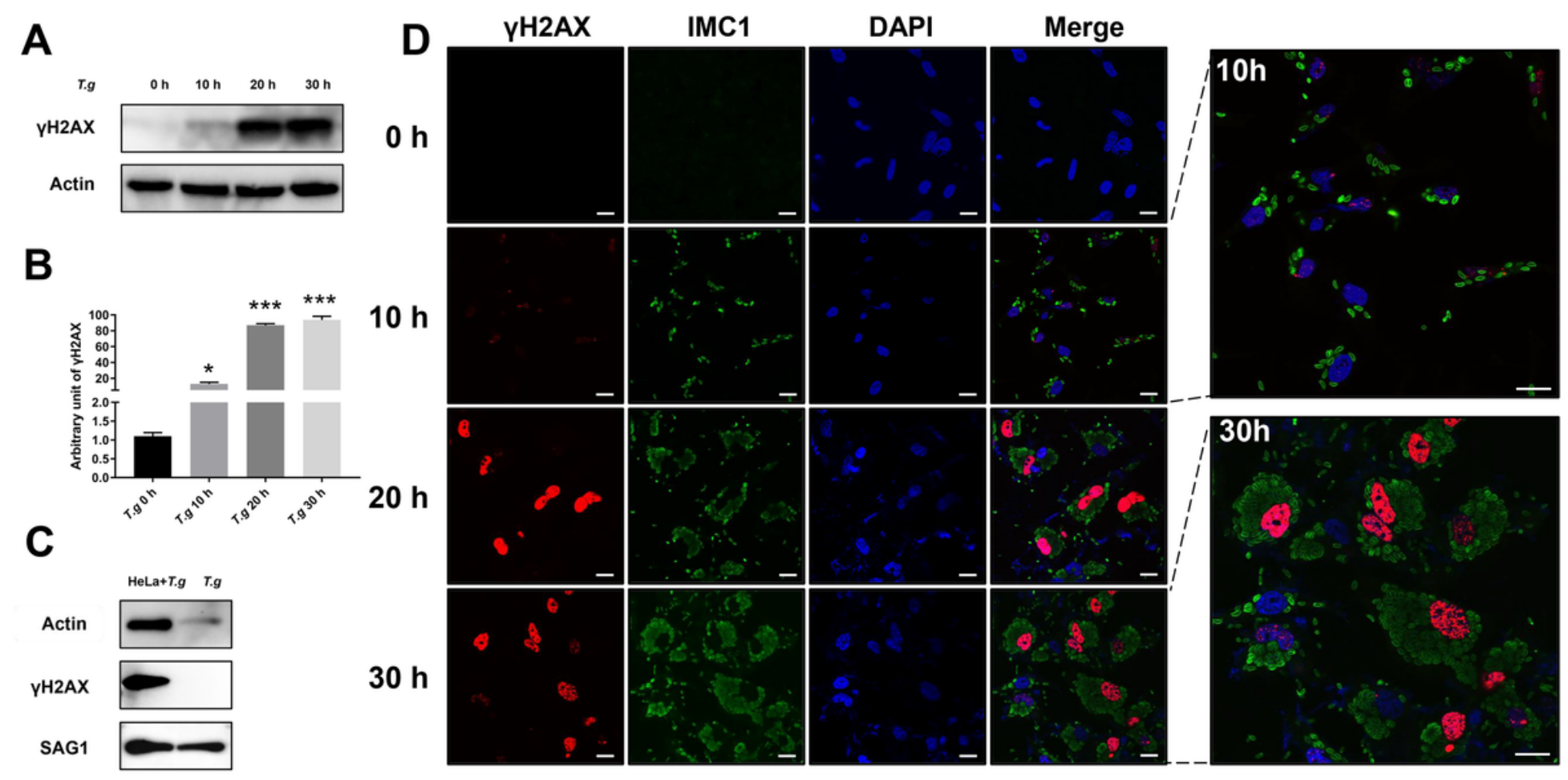

\section{Figure 1}

DNA damage of the T. gondii-infected host cells in vitro. A) HeLa cells were infected with T. gondii $\mathrm{RH} \triangle \mathrm{ku} 80$ at a MOI of 10:1. $\mathrm{YH} 2 \mathrm{AX}$ levels were detected by Western blot at $0 \mathrm{~h}$ (uninfected control), $10 \mathrm{~h}$, $20 \mathrm{~h}$ or $30 \mathrm{~h}$ post-infection. Actin was used as a loading control. B) Quantification of $\mathrm{YH} 2 \mathrm{AX}$ showed in figure A. Mean $\pm \mathrm{SD}(n=3)$ of $\mathrm{YH} 2 \mathrm{AX}$ levels are shown with that of uninfected cells set as one arbitrary unit. ${ }^{*} \mathrm{P} \leq 0.05$, ${ }^{\star \star \star} \mathrm{P} \leq 0.001$. C) $\mathrm{\gamma H} 2 \mathrm{AX}$ levels were measured by Western blot in T. gondii-infected HeLa cells and purified T. gondii parasites that were freshly isolated from infected Hela cells. Actin and SAG1 were used as a loading control for host cells and T. gondii, respectively. D) $\mathrm{YH} 2 \mathrm{AX}$ by immunofluorescence of uninfected $(0 \mathrm{~h})$ and infected HeLa cells at $10 \mathrm{~h}, 20 \mathrm{~h}$ or $30 \mathrm{~h}$ post-infection. IMC1 mouse serum and DAPI were used to indicate T. gondii and nuclei, respectively. red, $Y H 2 A X$; green, IMC1; blue, DAPI. Scale $=30 \mu \mathrm{m}$. All experiments were performed in triplicate. 
A

B
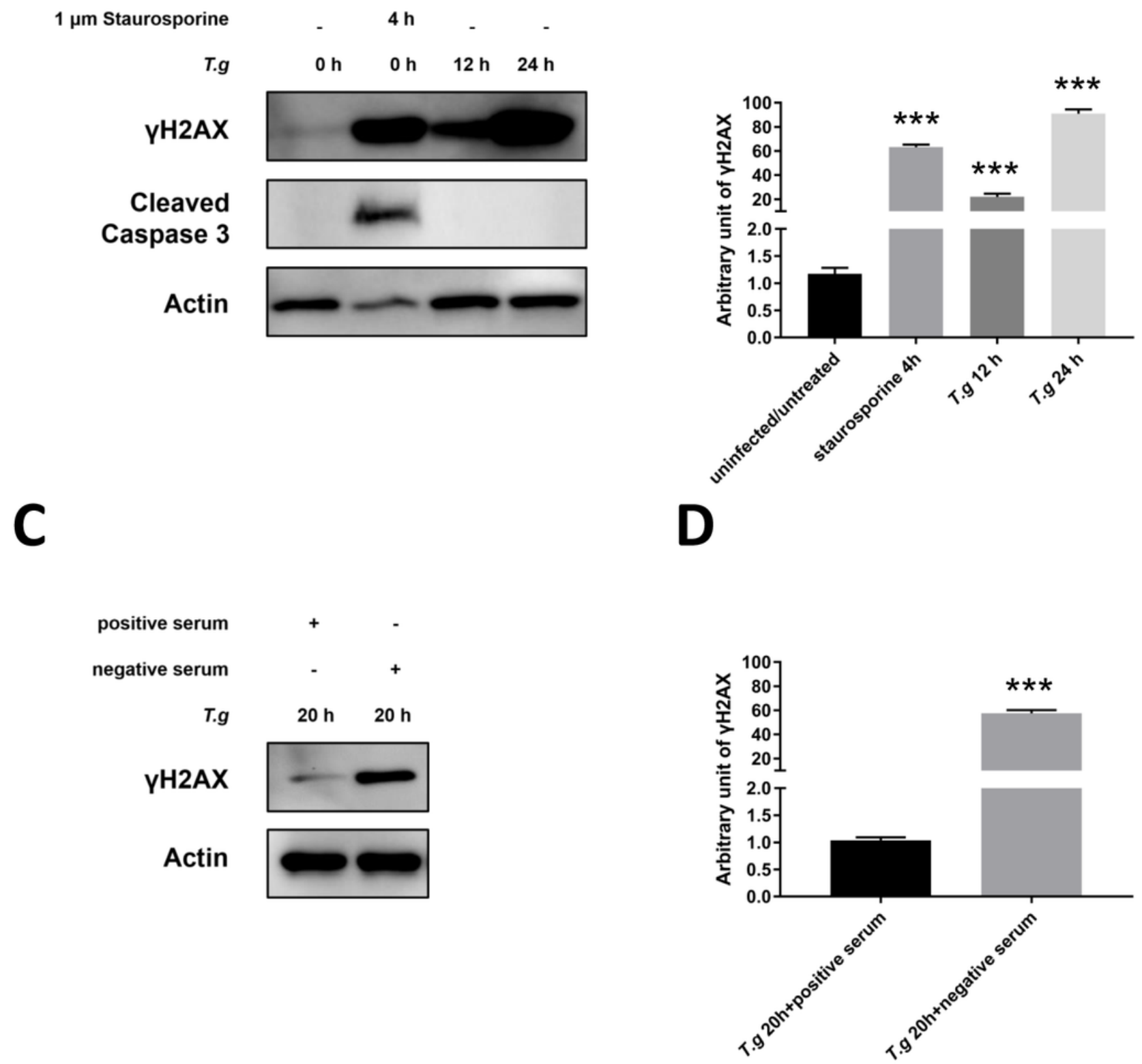

Figure 2

DSBs of T. gondii-host cells upon its invasion. A) Uninfected HeLa cells were treated with $1 \mu \mathrm{m}$ staurosporine for $4 \mathrm{~h}$ to induce apoptosis. Treated, uninfected and infected HeLa cells were harvested 12 $\mathrm{h}$ or $24 \mathrm{~h}$ later, $\mathrm{yH} 2 \mathrm{AX}$ and cleaved caspase 3 were detected by Western blot. B) Quantification of $\mathrm{yH} 2 \mathrm{AX}$ in figure $A$. Mean $\pm \mathrm{SD}(n=3)$ of $\mathrm{YH} 2 \mathrm{AX}$ levels are shown with that of uninfected cells set as one arbitrary unit. $* \star * \mathrm{P} \leq 0.001$. C) $\mathrm{YH} 2 \mathrm{AX}$ was detected by Western blot on HeLa cells $20 \mathrm{~h}$ PI with positive or negative serum-pretreated EGFP-RH $\triangle$ ku80. D) Quantification of $\mathrm{yH} 2 \mathrm{AX}$ in figure C. Mean $\pm \mathrm{SD}(\mathrm{n}=3)$ of $\mathrm{YH} 2 \mathrm{AX}$ levels are shown with that of uninfected cells set as one arbitrary unit. ${ }^{\star} \star \mathrm{P} \leq 0.001$. All experiments were performed in triplicate. 


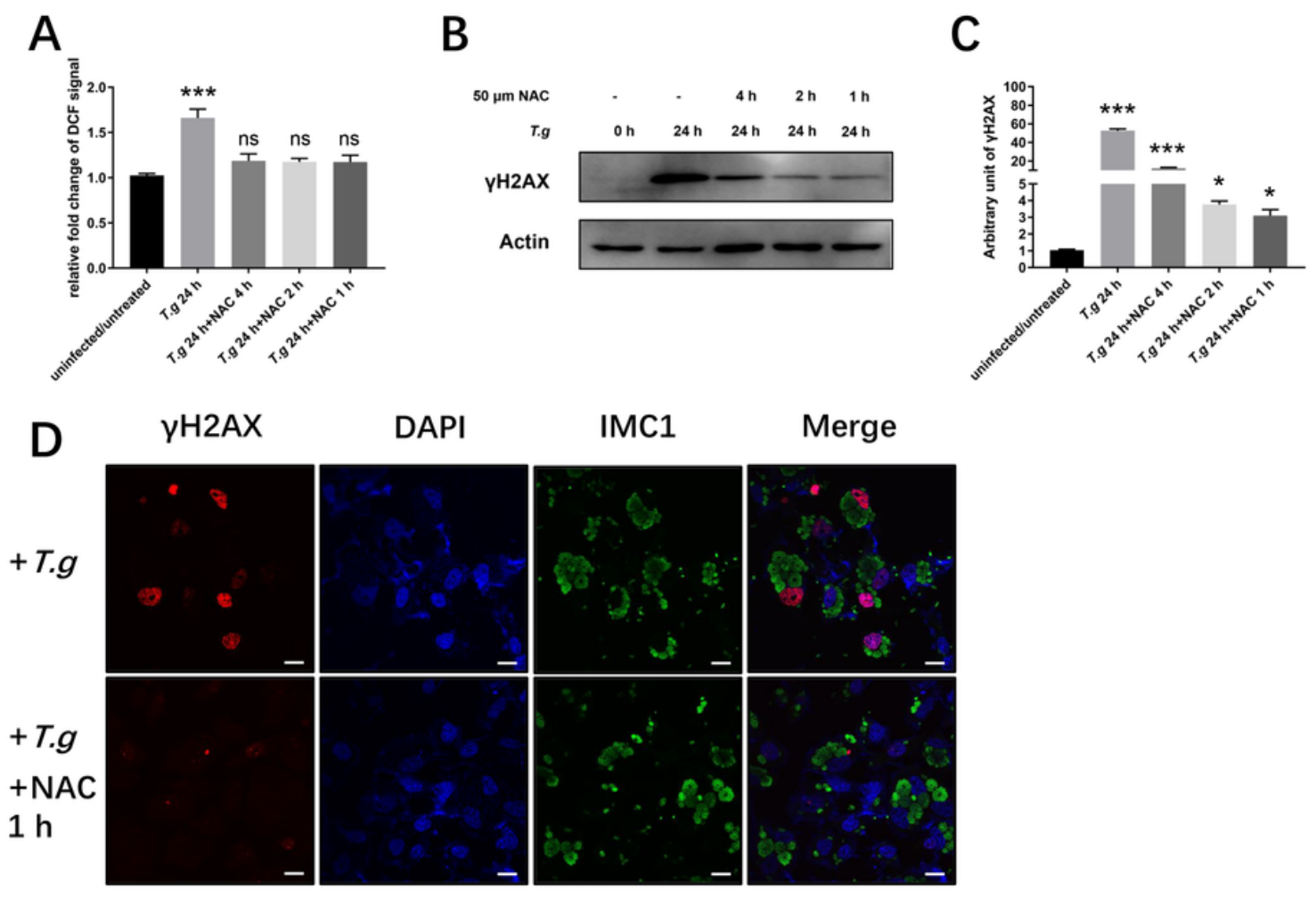

\section{Figure 3}

DNA damage associated with reactive oxygen species. A) HeLa cells were seeded in 24-well plate and infected with T. gondii RH $\triangle \mathrm{ku} 80$ at a MOI of $10: 1$ for $24 \mathrm{~h}$ when they were treated with $50 \mu \mathrm{m}$ NAC for 1, 2 or $4 \mathrm{~h}$ along with uninfected cells. All cells were then stained with $10 \mu \mathrm{m}$ H2DCFDA and fluorescence signals were recorded. Data are presented as mean $\pm S D(n=3)$, ${ }^{\star \star \star} P \leq 0.001$, ns: no significance. $\left.B\right)$ $\mathrm{yH} 2 \mathrm{AX}$ levels of HeLa cells treated in the same way as those cells in A) were measured by Western blot. C) Quantitative data of $\mathrm{yH} 2 \mathrm{AX}$ in figure B. Mean $\pm \mathrm{SD}(\mathrm{n}=3)$ of $\mathrm{yH} 2 \mathrm{AX}$ levels are shown with that of uninfected cells set as one arbitrary unit. ${ }^{*} P \leq 0.05,{ }^{\star} \star * P \leq 0.001$. D) HeLa cells were infected with $T$. gondii RH $\triangle$ ku80 at MOI of 10:1 for $24 \mathrm{~h}$ and treated with $50 \mu \mathrm{m}$ NAC for $1 \mathrm{~h}$, then assayed for $\mathrm{\gamma H} 2 \mathrm{AX}$ by Immunofluorescence. red, $\mathrm{YH} 2 \mathrm{AX}$; green, IMC1; blue, DAPI. Scale $=30 \mu \mathrm{m}$. All experiments were performed in triplicate. 
A

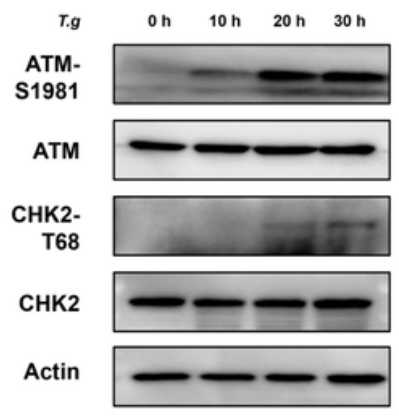

B

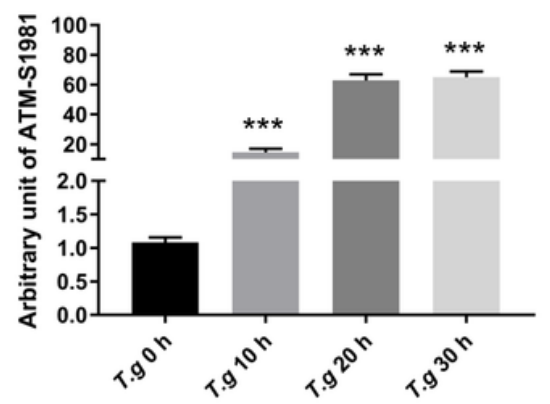

C

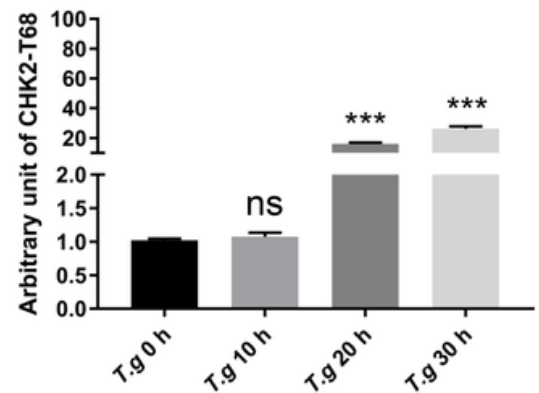

\section{Figure 4}

ATM/CHK2 activation upon T. gondii infection. A) HeLa cells were infected with T. gondii RH $\triangle \mathrm{ku} 80$ at a MOI of 10:1. Expression of ATM, ATM-S1981, CHK2 and CHK2-T68 were detected by Western blot at $0 \mathrm{~h}$ (uninfected control), $10 \mathrm{~h}, 20 \mathrm{~h}$ or $30 \mathrm{~h}$ post-infection. B) Quantitation of ATM-S1981 in figure A with ATMS1981 levels of uninfected cells set as one arbitrary unit. C) Quantitative data of CHK2-T68 in figure A with CHK2-T68 levels of uninfected cells set as one arbitrary unit. Data are presented as mean \pm SD ( $n=$ $3),{ }^{\star \star *} \mathrm{P} \leq 0.001$, ns: no significance. All experiments were performed in triplicate.

\section{Supplementary Files}

This is a list of supplementary files associated with this preprint. Click to download.

- GraphicalAbstract.jpg 